\title{
Concentração intraurbana de população e empregos: os centros antigos das cidades brasileiras perderam primazia?
}

\author{
Vanessa Gapriotti Nadalin* \\ Bernardo Alves Furtado ${ }^{\star *}$ \\ Matheus Rabetti ${ }^{\star \star \star}$
}

Os centros antigos das cidades são regiões internas às metrópoles que se destacam por seu valor simbólico e por estarem sujeitos à decadência e esvaziamento. Em geral, a configuração espacial da população e dos empregos determina a relevância locacional dos sítios urbanos, os fluxos de mobilidade e a própria vitalidade de cada porção urbana, inclusive o centro. Entretanto, informações de localização populacional intraurbana só são disponibilizadas a cada dez anos. Dados de localização de empregos, quando disponíveis, se encontram agregados e não estão georreferenciados. Nesse contexto, o presente trabalho analisa e identifica estruturas intraurbanas de população (1991, 2000 e 2010) e emprego (2002 e 2013), em 12 regiões metropolitanas brasileiras, utilizando áreas mínimas comparáveis para agregar dados populacionais censitários e geolocalização identificada de empregos. Os resultados indicam que há perda populacional nos centros metropolitanos no período 1991-2000, parcialmente recuperada no decênio seguinte. Constata-se ainda desconcentração de empregos com migração para novas áreas centrais, em relação aos centros urbanos tradicionais. Todavia, o comportamento não é linear para cada uma das 12 RMs analisadas e o resultado espacial final é específico para cada uma. 0 artigo contribui com a construção inédita da espacialização dos empregos para as 12 RMs. Ademais, a metodologia desenvolvida permite análise urbana quantitativa padronizada como apoio a pesquisadores com conhecimento local.

Palavras-chave: Emprego intraurbano. Áreas centrais urbanas. Deslocamento populacional. Densidade de Kernel. Regiões metropolitanas.

\footnotetext{
*Instituto de Pesquisas Econômicas Aplicadas (Ipea), Brasília-DF, Brasil (vanessa.nadalin@ipea.gov.br; https://orcid. org/0000-0002-1545-8490).

** Instituto de Pesquisas Econômicas Aplicadas (Ipea), Brasília-DF, Brasil (bernardo.furtado@ipea.gov.br; https://orcid. org/0000-0002-9598-7404).

*** Globo.com, Rio de Janeiro-RJ, Brasil (matheus.rabetti@gmail.com; https://orcid.org/0000-0003-1568-1809).
} 


\section{Introdução}

Cidades são palimpsestos vivos. Cidades representam o acumulado histórico, orgânico, de dinâmicas econômicas anteriores em constante mutação que se conformam em paisagem urbana (BENEVOLO, 1980; CULLEN, 1961; SITTE, 1889). Essencialmente, cidades se constroem por meio da localização de seus cidadãos, as residências, e da localização de seus centros de empregos: serviços, indústrias, comércios. E, claro, pessoas e veículos que fazem circular pessoas, produtos e ideias (JACOBS, 1970; STORPER; VENABLES, 2005).

Em países populosos como o Brasil,, ${ }^{1}$ acompanhar a localização de pessoas é tarefa árdua e complexa que resulta em contagem censitária com periodicidade apenas decenal. ${ }^{2}$ O emprego formal, por sua vez, é compulsoriamente registrado no Ministério do Trabalho e Emprego (MTE) por meio da Relação Anual de Informações Sociais (Rais). Entretanto, a divulgação dos dados da Rais é usualmente feita de forma agregada por atividades econômicas de acordo com a Classificação Nacional de Atividades Econômicas (CNAE), por ocupação, de acordo com a Classificação Brasileira de Ocupações (CBO), e por municípios.

Quando não se observa a localização de pessoas e empregos, perde-se, essencialmente, a capacidade de se observar a essência da dinâmica intraurbana. De fato, a presença tanto de residências quanto de atividades econômicas determina a percepção da vivacidade do espaço público, seu uso e, consequentemente, parte relevante do seu valor econômico. Esse conjunto de percepções é organizado e atribuído de forma sintética pelos cidadãos de acordo com bairros, ou neighborhoods, no termo em inglês (FURTADO, 2011; GALSTER, 2001; GRIGSBY et al., 1987; LYNCH; CAMARGO, 1960).

A análise urbana pós Jane Jacobs $(1970,2000)$ confirma inúmeros benefícios de densidades urbanas mais altas e uso misto, nos centros vivos de grandes metrópoles (GLAESER, 2012). Nakano (2015), em uma revisão recente, lista como vantagens: a eficiência econômica na oferta de infraestrutura e serviços aos cidadãos; a utilização de equipamentos públicos já disponíveis; o controle social; e a interação e vitalidade de regiões centrais altamente densas, além da melhor acessibilidade e acesso a oportunidades.

Dentre as desvantagens, Nakano menciona, por exemplo, o aumento da criminalidade e o congestionamento de trânsito. Bettencourt (2015) confirma que ganhos de escala urbana implicam, simultaneamente, maior criatividade, mas também maior criminalidade no âmbito da região metropolitana como um todo.

Ana Lúcia Rodrigues (2013), por sua vez, lembra que ambos - a alta criminalidade e a piora da acessibilidade - se concretizam prioritariamente nas periferias urbanas, a despeito das áreas centrais. Essa periferização das regiões metropolitanas, com prejuízo concentrado

\footnotetext{
${ }^{1}$ Nos Países Baixos, com cerca de 17 milhões de pessoas em 2016, o censo é atualizado em tempo real, com a obrigação de registro na Prefeitura com até três dias de chegada à localidade.

${ }^{2}$ A contagem populacional quinquenal e as estimativas populacionais feitas anualmente pelo Instituto Brasileiro de Geografia e Estatística (IBGE) informam apenas dados agregados por municípios.
} 
nos mais pobres, é confirmada para o caso de São Paulo pela literatura (NAKANO, 2015; MARQUES; REQUENA, 2013; NADALIN; IGLIORI, 2015).

Nesse contexto, o objetivo do presente artigo é calcular, apresentar e analisar a dinâmica locacional intraurbana populacional (1991, 2000 e 2010) e de empregos (2002 e 2013) para as 12 maiores regiões metropolitanas brasileiras, de acordo com a pesquisa Regiões de Influência das Cidades (Regic) (IBGE, 2008), utilizando dados censitários dos Censos Demográficos de 1991, 2000 e 2010 (IBGE, 1991, 2003, 2013) e dados georreferenciados da Rais (BRASIL, 2013). A análise é feita com base nos conceitos de: "áreas centrais de referência", historicamente construídas e usualmente denominadas de "centro"; e delimitação de "centralidades", definidas a partir da análise das concentrações de alta densidade de empregos construídas neste trabalho e em sintonia com a construção teórica de Gottdinier (1997), Villaça (1998) e Frúgoli Júnior (2000).

Destaca-se a análise conjunta das 12 regiões metropolitanas brasileiras, utilizando as mesmas bases de dados e metodologia. Assim, enseja-se descrever a dinâmica da estruturação urbana em perspectiva nacional. Para além da descrição, busca-se circunscrever a análise destas dinâmicas a partir da visão da sociologia urbana (SASSEN, 1998; FIX, 2007), que conecta a teoria de aglomeração intraurbana à lógica de produção do capitalismo globalizado. Dada a dificuldade em conseguir dados intraurbanos, a literatura corrente nacional restringe-se a apenas uma região metropolitana, ou mesmo apenas um bairro (ALVES et al., 2010; BERNARDINO; LACERDA, 2015; CUNHA, 2016; CUNHA et al., 2013; JANNUZZI; JANNUZZI, 2002; MARQUES, 2014).

As hipóteses de partida da pesquisa questionavam se haveria perda populacional nos "centros históricos" urbanos das metrópoles brasileiras. E, adicionalmente, se essa perda populacional se deveria a determinada perda de vitalidade, representada pela presença de comércio e oferta de serviços, ou seja, empregos, nessas áreas centrais. Em outras palavras, a pergunta orientadora da pesquisa é se os centros antigos conseguiram manter, por meio da presença de residências e atividade econômica, a primazia historicamente observada. Ou se, alternativamente, a dinâmica intraurbana de pessoas e empregos rompe essa estabilidade e novas configurações podem ser verificadas.

A análise realizada indica que, de fato, houve perda populacional no período 19912000 nas regiões centrais, definidas no trabalho como áreas centrais de referência. Essa perda é em parte recuperada no período seguinte (2000-2010). A dinâmica 2000-2010 é mais complexa, apresentando resultados mistos: manutenção da primazia das áreas centrais, com alterações marginais; e, simultaneamente, rearranjo de áreas centrais com criação de novos espaços centrais determinantes. Esses resultados estão em linha com aqueles encontrados por Marques e Requena (2013) e Nakano (2015), para São Paulo, e por Barcelona de Gay e Valverde (2008) e Ehrenhalt (2012), para o caso americano.

Em relação aos empregos, o trabalho propõe a conceituação de centralidades - regiões proporcionalmente com mais empregos do que o restante de cada metrópole - e as localiza espacialmente. Essas centralidades são então comparadas com as áreas centrais de referência. 
Finalmente, a análise espacial das centralidades nos dois períodos - 2002 e 2013 - permite a conceituação e localização das "novas centralidades", presentes apenas no período mais recente.

Com isso, caracteriza-se, no cômputo geral, no período 1991-2013, perda populacional e desconcentração dos empregos nas áreas urbanas centrais metropolitanas brasileiras. As distinções entre cada metrópole são apresentadas ao longo do texto.

Este artigo contribui com a literatura ao: consolidar e espacializar o conceito de "áreas centrais de referência”; realizar análise comparativa sistemática da evolução populacional das áreas centrais nos períodos 1991-2000 e 2000-2010; calcular, propor e espacializar - a partir do emprego privado - as "centralidades" e as "novas centralidades", de forma inédita, em escala intraurbana para o conjunto das 12 regiões metropolitanas brasileiras principais, vinculando, dessa forma, a análise do local de residência e do local de trabalho no âmbito das metrópoles; e adicionalmente realizar análise descritiva dos resultados obtidos. Finalmente, ressalve-se que parte da contribuição do trabalho consiste em disponibilizar informações quantitativas e espacialmente detalhadas a pesquisadores locais, de modo que o entendimento das idiossincrasias e vicissitudes próprias de cada região metropolitana possa complementar a análise do ponto de vista qualitativo. Mais do que isso, é oferecida análise econômica intraurbana das principais metrópoles brasileiras, até onde sabemos, ainda não disponível na literatura.

Além dessa introdução, o artigo apresenta a metodologia utilizada para cálculo das centralidades, as bases de dados, bem como os passos utilizados na construção dos conceitos. Posteriormente são mostrados os resultados espaciais dos conceitos de áreas centrais de referência e centralidades, a dinâmica populacional e as centralidades, novas centralidades e desconcentração de empregos. 0 texto conclui com algumas considerações finais.

\section{Conceitos da análise e metodologias}

Os passos metodológicos incluem a delimitação das áreas centrais de referência, a partir de dados documentais e cartográficos, a delimitação das centralidades, por meio da produção dos cartogramas com a densidade de empregos calculada para 2002 e 2013, e a construção das bases de dados utilizadas.

As áreas centrais podem ser descritas a partir de duas perspectivas: a do poder simbólico; e a do poder funcional e atrator. 0 poder simbólico identifica-se com a memória histórica, cultural e comunitária. Já o poder atrator tem característica funcional, que implica convergência de fluxos e múltiplas atividades, ao configurar polos de empregos (BRASIL, 2005). Neste trabalho, as áreas centrais de referência se caracterizam pelo seu poder simbólico, construído, e as centralidades por seu caráter funcional.

Áreas centrais de referência

A delimitação das áreas centrais de referência baseou-se na existência de fronteiras de bairros denominados “centro". Buscaram-se informações oficiais explicitadas nos Planos 
Diretores Municipais ou em mapas oficiais com indicação de nomes de bairros, ou ainda em Leis de Zoneamento ou de Uso e Ocupação do Solo.

Essa delimitação foi visualmente sobreposta aos limites das áreas mínimas comparáveis de setores censitários (AMCs). A partir dos mapas oficiais de divisão e bairros, identificaram-se as vias que constituem os limites dos mesmos. Então os polígonos vetoriais das AMCs foram sobrepostos à malha de ruas e visualmente foram escolhidas as AMCs que estavam mais próximas daqueles limites.

A compatibilização dos setores censitários entre si para 1991, 2000 e 2010 só foi possível graças à construção das áreas mínimas comparáveis para setores censitários disponibilizadas por Mation (no prelo), similar à realizada por Ehrl (2017) para municípios.

\section{Centralidades}

A delimitação das centralidades foi realizada por meio da suavização do padrão espacial de distribuição de empregos e estabelecimentos a partir da localização geográfica dos estabelecimentos da Rais. Identificamos áreas de maior concentração de empregos e empresas. As informações disponíveis impuseram o limite temporal da análise entre 2002 e 2013. Não analisamos os anos contidos nesse intervalo temporal, pois consideramos que a dinâmica de alteração da estrutura urbana de localização e concentração de empregos é lenta, de maneira que anualmente não seriam observadas mudanças significativas.

Adicionalmente, utilizou-se um algoritmo proprietário da empresa Imagem, distribuidor ESRI no Brasil, que permite geocodificar endereços. Para 2013, 6,4\% dos endereços não puderam ser localizados, enquanto $81,3 \%$ foram geolocalizados com precisão máxima, encontrando exatamente o nome da rua e número.

A geocodificação da Rais resulta em um mapa de pontos de estabelecimentos, contendo o número de empregados associados a eles, que foi utilizado para gerar mapas de calor - ou seja, densidade de Kernel em duas dimensões. A densidade de Kernel é uma técnica não paramétrica empregada para estimar a função densidade de probabilidade de uma variável aleatória, que esteja na média entre os pontos de dados observados. Ela consiste em uma generalização da ideia tradicional de densidade, com estimativa de densidade, ou intensidade do processo, dada pela fórmula:

$\hat{\gamma}=\frac{\#(S E A)}{a}$

Onde \#(SEA) é o número de eventos do padrão de pontos $S$ dentro da área $A$; $a$ é a região de estudo, e $\hat{\gamma}$ os valores de densidade representados pelas cores do mapa de calor (O’SULLIVAN; UNWIN, 2014).

O Kernel - ou seja, a janela aberta para criar essa superfície - teve o formato de função gaussiana e, para a escolha do tamanho dessa janela - o bandwidth - foi utilizado o método asymptotic mean integrated squared error (Amise). Essas também foram as escolhas metodológicas de Leslie (2010). A metodologia para delinear áreas centrais por meio de superfícies de Kernel também foi empregada por Thurstain-Goodwin e Unwin (2000). 
Foi feito um mapa de calor tanto para o padrão de pontos de estabelecimentos como para o padrão de pontos dos empregos para cada região metropolitana estudada, levando em conta a área urbanizada da região. ${ }^{3}$ Assim, busca-se limitar a importância de estabelecimentos isolados que apresentem grande número de empregados, valorizando as regiões que atraem mais de um estabelecimento.

Consideram-se áreas de altas densidades aquelas com densidade superior à média mais três desvios padrão, tanto na superfície da densidade de empregos, quanto na de estabelecimentos. No caso da medida de concentração espacial de empregos e empresas utilizada, espera-se uma variabilidade muito grande nos valores, uma vez que cada observação corresponde a um pixel pequeno em uma figura raster que abarca toda a área urbanizada de uma região metropolitana. A escolha da regra pela qual identificar observações “muito grandes” é semelhante à de identificar observações outliers. A escolha por uma determinada regra sempre acaba sendo em alguma medida ad hoc. A diferença é que aqui sabemos que as observações muito grandes foram geradas pelo mesmo "processo gerador de dados" que as demais.

Apesar de cada RM em cada momento do tempo apresentar um valor de corte diferente, a regra única de média mais três desvios padrão se mostrou suficientemente válida para o conjunto de todas as áreas urbanas estudadas, ou seja, revelou de maneira suficiente a estrutura urbana. Assim, foram levadas em conta as especificidades de cada área, mas manteve-se uma regra em comum que permite a comparação entre elas.

A partir da comparação entre as centralidades existentes em 2002 e aquelas presentes em 2013, identificaram-se as que surgiram em 2013, denominadas de novas centralidades.

A superfície de densidade de Kernel é calculada por meio de janelas espaciais móveis (o Kernel propriamente dito), a partir das informações pontuais de localização de emprego. Isso significa que padrões espaciais locais distintos geram superfícies distintas. Sobre essas superfícies, aplica-se um plano horizontal de acordo com o valor de corte estabelecido. Uma vez feita essa delimitação das centralidades, computa-se o total de empregos no interior dessas regiões. Nesse caso, diferentes comportamentos da superfície interna às centralidades (diferentes padrões espaciais) podem gerar diferentes totais de empregos. A título de exemplo, considere uma centralidade em que toda sua área interna apresenta uma densidade de Kernel constante, igual à densidade de Kernel de corte. Essa centralidade terá um total de empregos menor do que uma centralidade de mesma área, porém na qual a densidade aumenta em seu interior. Desse modo, a metodologia identifica justamente regiões de mais alta concentração espacial de empregos, a despeito de densidades similares na fronteira do corte. ${ }^{4}$

\footnotetext{
${ }^{3}$ A delimitação das áreas urbanizadas das grandes aglomerações urbanas brasileiras foi feita pelo IBGE para 2005 e está disponivel em: 〈http://www.ibge.gov.br/home/geociencias/geografia/geografia_urbana/areas_urbanizadas/default. shtm>. Acesso em: 03 jul. 2015.

${ }^{4}$ Para uma discussão sobre mensuração de concentração espacial, veja Pereira et al. (2013).
} 


\section{Bases de dados}

Foram utilizadas as informações do universo dos Censos Demográficos de 1991, 2000 e 2010, do IBGE, agregadas por setores censitários, assim como os dados da sinopse preliminar agregados por setores censitários em 2000 e 2010, relativos ao estoque total de domicílios recenseados e estoque de domicílios vagos (IBGE, 1991, 2003, 2013).

Também foram consideradas as informações da Rais de 2002 e 2013, principalmente o total de vínculos ativos, setor da atividade econômica da empresa, classificado segundo a CNAE 1.0 e o endereço do estabelecimento.

A preparação dos dados incluiu o tratamento a uma inconsistência relevante, referente à localização correta dos empregos. Essa inconsistência decorre da declaração de número elevado e não fidedigno de empregados de toda uma rede, como se trabalhassem em somente um endereço. A título de exemplo, tomem-se todos os empregados de uma dada Prefeitura Municipal que informa como se o local de trabalho de todos os funcionários municipais fosse a localização da sede da Secretaria de Recursos Humanos.

No intuito de minimizar essas ocorrências, derivadas da informação original fornecida pelas empresas ao MTE, optamos pela identificação de setores problemáticos por meio da CNAE 1.0. Todos os estabelecimentos de administração pública, defesa e seguridade social (código 75) tiveram seus vínculos de emprego igualados a zero, dada sua baixa confiabilidade. Os empregados foram desconsiderados, sendo que apenas os estabelecimentos foram admitidos no cálculo da superfície de densidade de estabelecimentos. Já para os setores 40: eletricidade, gás e água quente, 41: captação, tratamento e distribuição de água, 60: transporte terrestre, 62: transporte aéreo, 74: serviços prestados principalmente a empresas e 90: limpeza urbana e esgoto, foi feito procedimento de imputação de valores, substituindo-se os valores extremos pelo valor mediano do setor.

Considere-se, assim, que a análise se restringe em grande parte aos dados dos setores tipicamente privados, excluindo-se os empregos públicos, devido à limitação original da base de dados. Dessa forma, a análise corre o risco de apresentar um viés a favor da concentração, caso os setores privados sejam mais concentrados do que os públicos.

\section{Resultados: delimitações conceituais e espaciais}

\section{Os perímetros das áreas centrais de referência e o poder simbólico}

A identificação de bairros autodenominados de "centros" pressupôs que os planejadores urbanos, ao delimitarem uma área com esse nome, estariam levando em conta tanto o poder simbólico da área quanto o poder atrator, funcional.

Os processos de planejamento territorial e regulação do uso do solo frequentemente contam com a participação da população, fato que em algum nível legitima que a delimitação oficial do bairro centro realmente reflita o poder simbólico percebido por essa população (FURTADO, 2011; GALSTER, 2001). A administração da cidade pressupõe que as 
principais funções se concentram no bairro denominado centro, pois para esta área há uma convergência de fluxos inequívoca, que deve ser organizada pelo poder público municipal.

Ao avaliar conjuntamente todos os perímetros de áreas centrais e os trechos dos planos locais que justificam sua escolha, notamos que muitos de fato se identificam com a área de poder simbólico, para além da região de confluência de fluxos.

No entanto, nas cidades planejadas (Belo Horizonte, Goiânia e Brasília), a delimitação do bairro central tem origem no primeiro plano de construção dessas cidades, com denominações de hipercentro, setor central e plano piloto. Essas delimitações não decorrem de reconhecimento municipal local do papel simbólico que teria se acumulado na memória comunitária, não se trata exatamente de centros antigos, mas sim de centros planejados.

Em outras cidades, a carga simbólica não está compreendida totalmente no bairro “centro" escolhido. Em Belém, por exemplo, não havia um bairro denominado de centro. Escolheu-se o bairro intitulado Cidade Velha. No entanto, o centro histórico também compreende parte do bairro Campina. Já em Salvador, há um bairro denominado Centro e um bairro distinto chamado de Centro Histórico. Em Curitiba, existe um bairro central histórico (São Francisco), vizinho ao bairro Centro, mas não pertencente a este.

Já em Porto Alegre, Recife, Fortaleza, Rio de Janeiro e Manaus, os perímetros escoIhidos correspondiam a bairros denominados de "centro histórico", "centro principal" e "centro". Em São Paulo, os bairros escolhidos (Sé e República) conformam, em grande parte, a operação urbana centro. Nesses casos, os centros englobam os centros históricos e marcos zeros dessas cidades.

Assim, em metade das metrópoles estudadas, os bairros delimitados pelos planejadores urbanos com nomes similares a "centro" correspondiam exatamente às áreas de poder simbólico e memória comunitária. Nas cidades em que isso não ocorreu, os bairros identificados possuem parte do poder simbólico, que é dividido com bairros vizinhos. Já nas cidades planejadas, o conceito de poder simbólico é diferenciado, ficando difícil aferir seu papel atrator a partir da memória comunitária.

Os perímetros das áreas centrais de referência e o poder funcional e atrator.

Em comparação com outras atividades, o trabalho é a atividade que presumivelmente possui maior poder atrator. Outras atividades atratoras - como lazer, estudos, compras e cuidados com a saúde - não foram mapeadas. Na metrópole de São Paulo, quando consideradas as viagens atraídas pela zona de origem e destino correspondente à área central de referência, verifica-se que $61 \%$ desses deslocamentos têm como motivo o trabalho. Nesse caso, o trabalho de fato é a maior atividade atratora de fluxos. ${ }^{5}$

A seguir, fazemos uma breve descrição da delimitação dos perímetros das áreas centrais de referência diante dos resultados das áreas de concentração de empregos e

\footnotetext{
5 Informação disponível em: 〈http://www.metro.sp.gov.br/metro/numeros-pesquisa/pesquisa-origem-destino-2007. aspx>. Acesso em: 7 out. 2015.
} 
empresas, com vistas a identificar o quanto essas áreas centrais de fato possuem poder funcional e atrator. ${ }^{6}$

Em Belém, o bairro Cidade Velha não é concentrador de empregos, porém, o bairro Campina, seu vizinho, é, sendo que este também possui parte da área reconhecida como centro histórico. A maior e principal mancha concentradora de empregos e empresas também se estende por outros bairros vizinhos, como Nazaré, Batista Campos e São Brás. 0 bairro de Umarizal - área nobre e de forte verticalização recente - é um foco de concentração de empregos, que se conectou com essa mancha maior entre 2002 e 2013.

\section{FIGURA 1}

Área central de referência e centralidades Salvador - 2002-2013

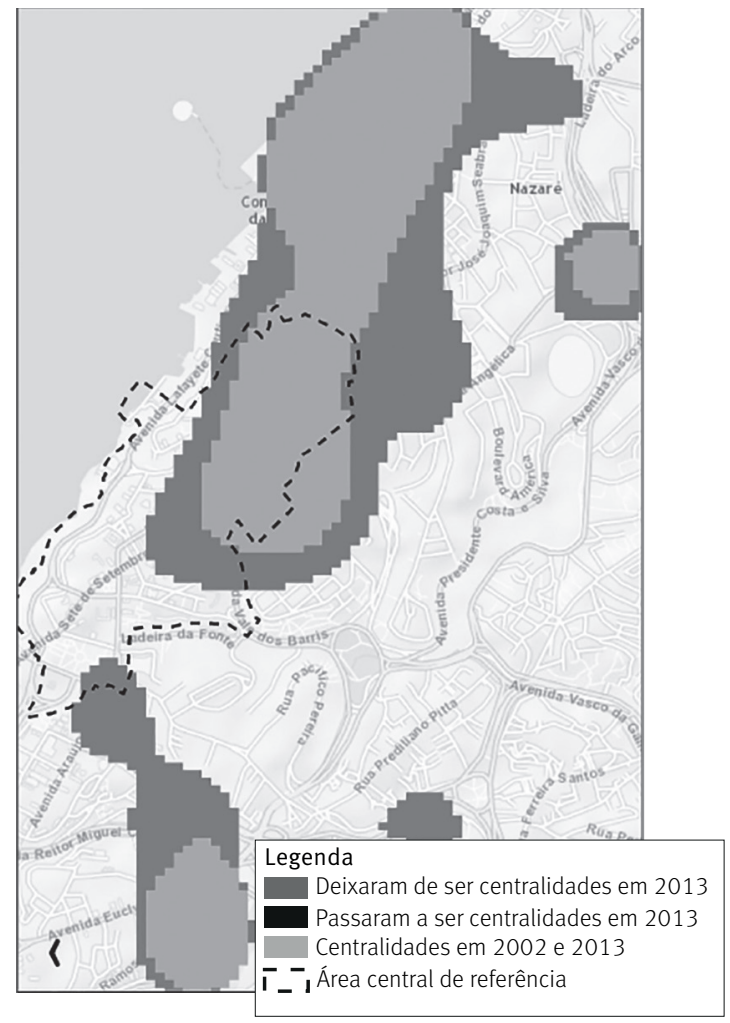

Fonte: Ministério do Trabalho e Emprego. Dados da Rais.

Em Salvador acontece algo semelhante. 0 bairro Centro possui concentração de empregos em parte de sua área e, além disso, não apresenta característica histórica, que é preponderante no bairro vizinho, o Centro Histórico. Este bairro tem alguma concentração de empregos, assim como sua continuação, o bairro de Comércio. Tal diferenciação de

\footnotetext{
${ }^{6}$ Adicionalmente, disponibilizamos (de forma anônima na internet) os mapas de todas as RMs analisadas, em cores e em formato interativo: 〈https://www.dropbox.com/sh/lk19cqs0qvhbewx/AAAjOEJ20dUk-SRMo2plJh-Ba?dl=0〉. É necessário dar download do arquivo para visualizá-lo corretamente.
} 
funções em centralidades vizinhas está reconhecida no texto do Plano Diretor, em que os três centros são tratados em conjunto como Centro Municipal Tradicional.

Já em Curitiba, a principal mancha contínua de concentração de empregos é muito maior do que as demais, mas não abarca parte do centro histórico, que lhe é contígua. Outro bairro vizinho que faz parte da mancha de concentração de empregos é o bairro Batel, residencial de alta renda e que concentra opções de lazer.

0 perímetro da área central de Manaus engloba todo o centro histórico e concentra uma grande parte da centralidade de empregos, que diminuiu de 2002 para 2013. Outra área de concentração de empregos está deslocada da região do perímetro, seguindo próxima à avenida Constantino Nery.

Nas cidades planejadas, começamos pelo caso mais emblemático, Brasília. O perímetro delimitado como a área central de referência corresponde à área tombada devido ao seu valor histórico. A Esplanada dos Ministérios, símbolo da capital do país, não mostrou a densidade de empregos e empresas necessária para conformar uma área com poder atrator funcional. Na área tombada, os setores "centrais" no sentido geográfico do Plano Piloto - porque estão próximos ao cruzamento do Eixo Monumental e do Eixo Norte-Sul conformaram a área de poder funcional atrator.

Em Goiânia - cidade pouco mais antiga que Brasília, pois foi fundada em 1935 -, o Setor Central também parece maior do que a área simbólica e a área com poder funcional. Há porções de concentração de empregos no perímetro do bairro Setor Central. Mais uma vez, devido ao caráter planejado, é nesse bairro que se concentram as atividades das administrações estadual e municipal. Existem outras manchas de concentração de empregos de porte considerável na cidade. A mais próxima da área central de referência corresponde ao Setor Oeste, bairro nobre da cidade.

Já Belo Horizonte, a cidade planejada mais antiga, foi inaugurada em 1897. Assim, de fato, o bairro Hipercentro corresponde ao primeiro núcleo construído e planejado como cidade. Portanto, nesse caso, o centro concentra sim todo o poder simbólico e histórico, além de também estar totalmente coberto por área de concentração de empregos e empresas. Belo Horizonte tem uma grande mancha central funcional que vai muito além dos limites do centro. Essa mancha contínua compreende também um bairro prioritariamente residencial dos mais nobres de Belo Horizonte, a Savassi.

Notamos que esse padrão - em que o perímetro delimitado como área central de referência abarca todo o centro histórico e, ao mesmo tempo, é coberto em grande parte pela área de concentração de empregos e empresas - também acontece em Fortaleza, Porto Alegre e São Paulo. 0 interessante é que nessas cidades - assim como em Belo Horizonte - existe uma mancha de concentração de empregos muito grande e contínua, que extravasa a área central e chega a bairros vizinhos que, se não são os mais nobres dessas cidades, estão entre estes. Em Fortaleza, a mancha não é contínua espacialmente, mas há grande proximidade entre as manchas correspondentes ao centro e aos bairros 
de Aldeota e Dionísio Torres. Em Porto Alegre, em 2013, as manchas de centralidades do centro e do bairro de Moinhos de Vento já estavam conectadas.

\section{FIGURA 2}

Área central de referência e centralidades Fortaleza - 2002-2013

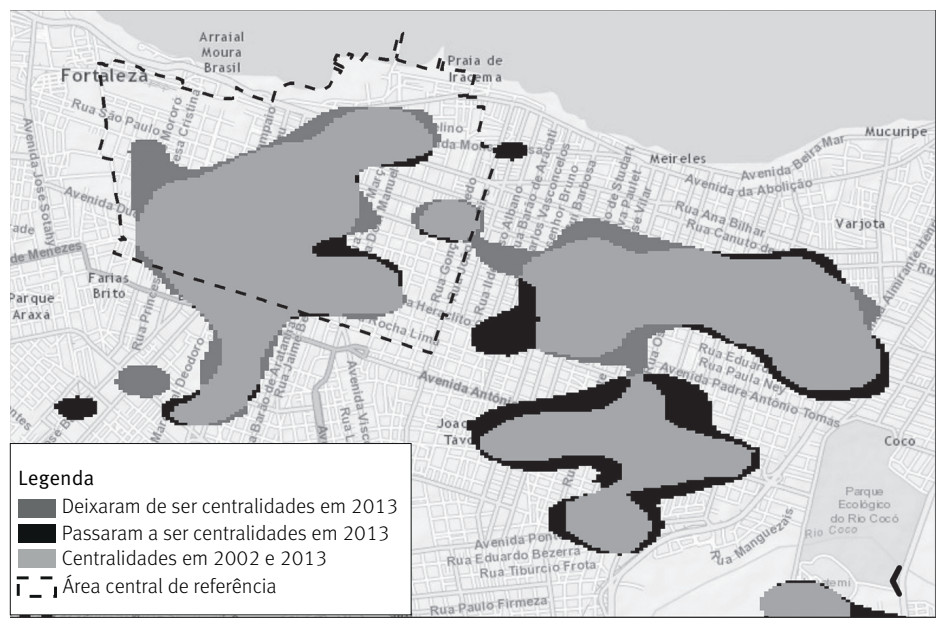

Fonte: Ministério do Trabalho e Emprego. Dados da Rais.

Já em São Paulo, essa mancha grande e contínua abarca parte do bairro nobre de Higienópolis, um outro polo de centralidade, que é a Avenida Paulista, e parte do bairro nobre de Jardim Paulista, ambos na direção sudoeste da área central. Já na direção norte e nordeste, existem duas manchas muito próximas que correspondem aos bairros de Bom Retiro e Brás/Pari, nos quais há produção e comércio de peças de vestuário.

Em Recife, cidade com bastante história, verificamos que o perímetro da área central de referência, que abarca toda a área histórica, não é totalmente coberto pela mancha de concentração de empregos e empresas. Recife tem uma característica diferenciada, pois possui dois polos claros de concentração de empregos. Além do polo central já mencionado, há o bairro de Boa Viagem, mais um bairro nobre residencial que concentra empregos, mas - no caso da cidade - geograficamente independente do polo central.

\section{Resultados: dinâmica populacional}

Uma das hipóteses da pesquisa foi a de que houve perda populacional nas áreas centrais de referência. 0 estudo indica um padrão forte para as 12 regiões metropolitanas estudadas: perda de população, entre 1991 e 2000, e recuperação, entre 2000 e 2010.

Entre 2000 e 2010, duas áreas centrais (Goiânia e Salvador) apresentaram decréscimo populacional, embora em intensidade bem pequena. Além disso, quase todas as cidades que recuperaram população não voltaram aos patamares populacionais de 1991. 0 Gráfico 1 traz mais detalhes sobre o crescimento populacional. 
GRÁFICO 1

Crescimento populacional nas áreas centrais de referência - 1991-2010

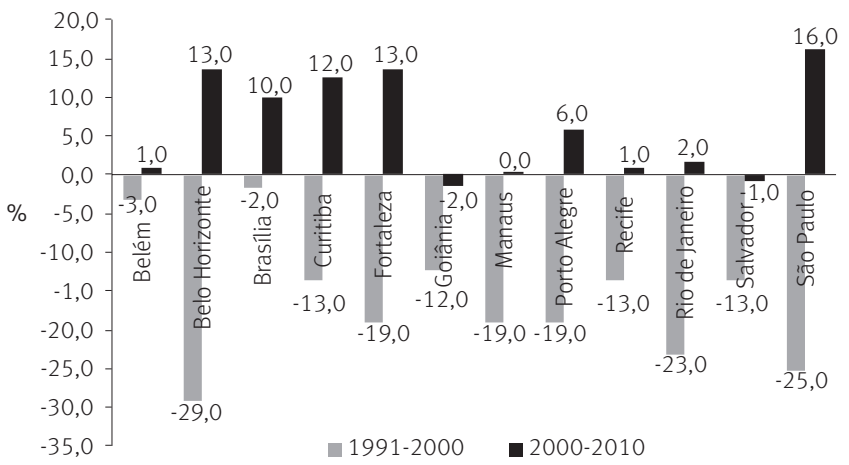

Fonte: IBGE (1991, 2000, 2010).

\section{Diminuição do estoque imobiliário vago}

Com relação à análise do estoque imobiliário residencial vago nas áreas centrais de referência - outra hipótese de pesquisa -, identificamos presença marcante de domicílios vagos nessas áreas. A taxa de vacância, que mede esse estoque em relação ao total de domicílios recenseados, varia de $8 \%$ a $24 \%$. Mesmo assim, entre 2000 e 2010 , o estoque de domicílios vagos diminuiu em todas as áreas centrais de referência, com exceção de Brasília e Goiânia, onde praticamente se mostrou estável. Isso se traduziu em queda das taxas de vacância nesse período, com exceção de Brasília. A presença de estoque vago é maior nas áreas centrais do que nos municípios e regiões metropolitanas (RMs), em todas as cidades estudadas, com exceção de Goiânia.

GRÁFICO 2

Taxa de vacância dos domicílios particulares permanentes nas áreas centrais de referência - 2000-2010

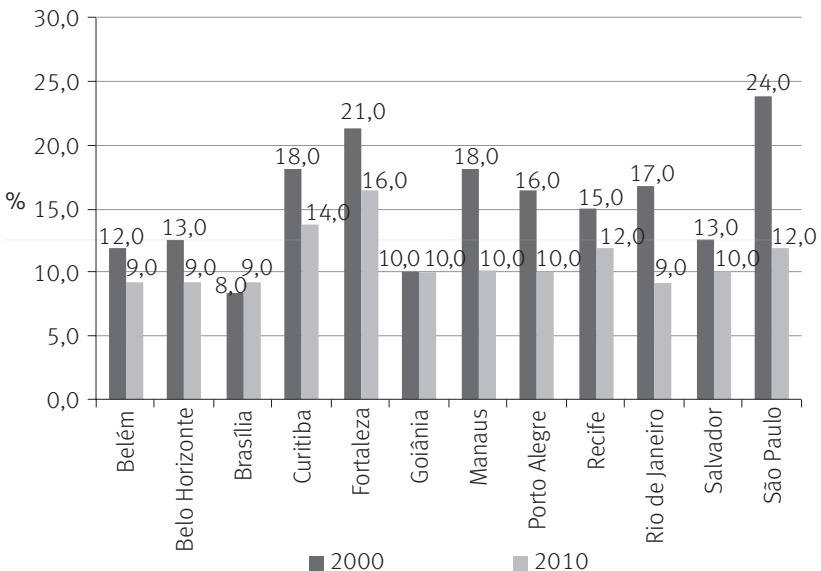

Fonte: IBGE (2000, 2010). 


\section{Resultados: centralidades urbanas do ponto de vista do emprego}

\section{Deslocamento da atividade econômica}

Com relação às atividades econômicas, em todas as áreas centrais de referência estudadas, houve crescimento de empregos entre 2002 e 2013, como mostra o Gráfico 3. Tal aumento também se verificou no número de estabelecimentos nesse mesmo período.

GRÁFICO 3

Total de empregos nas áreas centrais de referência - 2002-2013

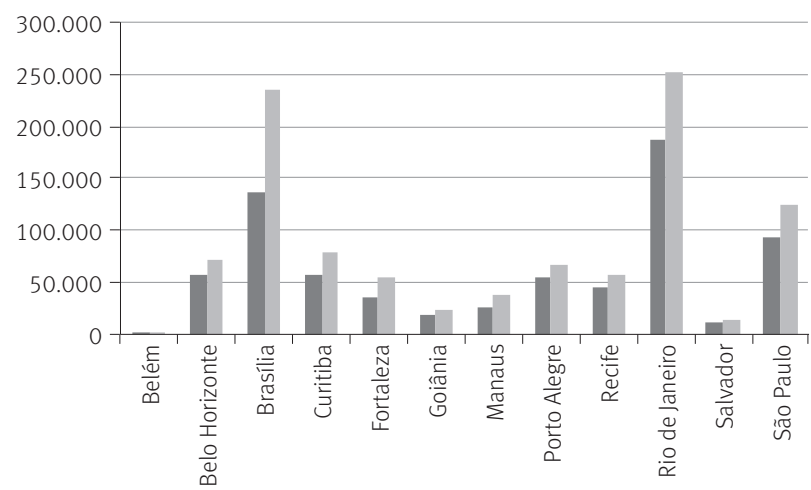

$2002 \quad 2013$

Fonte: Ministério do Trabalho e Emprego. Dados da Rais.

Mesmo assim, esse crescimento de empregos nas áreas centrais de todas as cidades foi menor do que aquele registrado para o total dos respectivos municípios e RMs. Assim, verificou-se uma desconcentração desses empregos centrais em todas as cidades, ilustrada na Tabela 1. Em algumas cidades, essa desconcentração é bem suave, principalmente naquelas cuja proporção dos empregos na área central já não era tão grande.

TABELA 1

Evolução da concentração de empregos nas áreas centrais de referência - 2002-2013

\begin{tabular}{|c|c|c|c|c|c|c|}
\hline \multirow{3}{*}{ Municípios } & \multirow{2}{*}{\multicolumn{3}{|c|}{$\begin{array}{c}\text { Proporção de empregos nas áreas centrais } \\
\text { em relação ao total do município }\end{array}$}} & \multirow{2}{*}{\multicolumn{3}{|c|}{$\begin{array}{l}\text { Em porcentage } \\
\text { Proporção de empregos nas áreas } \\
\text { centrais em relação ao total da RM }\end{array}$}} \\
\hline & & & & & & \\
\hline & 2002 & 2013 & Variação & 2002 & 2013 & Variação \\
\hline Manaus & 18,0 & 11,0 & $-7,1$ & 18,0 & 10,0 & $-7,1$ \\
\hline Brasília & 44,0 & 39,0 & $-4,5$ & 40,0 & 35,0 & $-5,0$ \\
\hline Recife & 18,0 & 12,0 & $-6,0$ & 13,0 & 8,0 & $-4,7$ \\
\hline Curitiba & 16,0 & 14,0 & $-2,5$ & 12,0 & 10,0 & $-2,7$ \\
\hline Goiânia & 9,0 & 6,0 & $-2,5$ & 7,0 & 5,0 & $-2,5$ \\
\hline Belo Horizonte & 12,0 & 9,0 & $-2,5$ & 8,0 & 6,0 & $-2,4$ \\
\hline Rio de Janeiro & 17,0 & 15,0 & $-2,2$ & 13,0 & 11,0 & $-2,2$ \\
\hline Fortaleza & 13,0 & 10,0 & $-2,4$ & 10,0 & 8,0 & $-2,2$ \\
\hline Porto Alegre & 18,0 & 14,0 & $-3,6$ & 9,0 & 7,0 & $-1,7$ \\
\hline Salvador & 4,0 & 3,0 & $-1,4$ & 4,0 & 2,0 & $-1,3$ \\
\hline São Paulo & 5,0 & 4,0 & $-1,0$ & 3,0 & 3,0 & $-0,7$ \\
\hline Belém & 2,0 & 1,0 & $-0,6$ & 1,0 & 1,0 & $-0,5$ \\
\hline
\end{tabular}

Fonte: Ministério do Trabalho e Emprego. Dados da Rais. 
Como mencionaremos a seguir, novas centralidades foram formadas. Alguns empregos de fato saíram desses centros tradicionais ou a criação de novos empregos já não ocorreu lá, mas sim nas novas centralidades.

Dinâmica de empregos nas áreas centrais de referência, centralidades e novas centralidades

Em termos quantitativos, a Tabela 2 traz a informação do total de empregos nas áreas centrais de referência e nas centralidades. Com exceção de Brasília, as centralidades têm total de empregos maior do que as áreas centrais de referência (centros). Tanto as centralidades como os centros cresceram em número de empregos, de 2002 a 2013. Mesmo assim, os empregos vêm aumentando mais nas centralidades do que nas áreas centrais de referência.

TABELA 2

Total de empregos nas áreas centrais de referência e centralidades - 2002-2013

\begin{tabular}{lrrrrrrrr}
\hline \multirow{2}{*}{ Municípios } & \multicolumn{2}{c}{$\mathbf{2 0 0 2}$} & & \multicolumn{2}{c}{$\mathbf{2 0 1 3}$} & & \multicolumn{2}{c}{ Crescimento (\%) } \\
\cline { 2 - 5 } \cline { 7 - 8 } \cline { 7 - 8 } & $\begin{array}{c}\text { Áreas } \\
\text { centrais }\end{array}$ & Centralidades & & $\begin{array}{c}\text { Áreas } \\
\text { centrais }\end{array}$ & Centralidades & & $\begin{array}{c}\text { Áreas } \\
\text { centrais }\end{array}$ & Centralidades \\
\hline Manaus & 26.611 & 28.680 & & 37.979 & 56.884 & & 43,0 & 98,0 \\
Goiânia & 19.346 & 46.134 & & 22.998 & 80.729 & & 19,0 & 75,0 \\
Belém & 2.013 & 56.796 & & 2.237 & 101.735 & & 11,0 & 79,0 \\
Curitiba & 57.735 & 81.282 & & 78.468 & 134.559 & & 36,0 & 66,0 \\
Porto Alegre & 54.928 & 88.708 & & 66.747 & 135.693 & & 22,0 & 53,0 \\
Recife & 44.771 & 81.004 & & 56.362 & 142.661 & & 26,0 & 76,0 \\
Fortaleza & 34.844 & 97.094 & & 54.799 & 146.881 & & 57,0 & 51,0 \\
Brasília & 135.590 & 88.184 & & 235.217 & 148.532 & & 73,0 & 68,0 \\
Salvador & 12.112 & 84.347 & & 14.990 & 166.925 & & 24,0 & 98,0 \\
Belo Horizonte & 56.135 & 217.587 & & 70.562 & 310.640 & & 26,0 & 43,0 \\
Rio de Janeiro & 187.986 & 506.654 & & 252.903 & 736.253 & & 35,0 & 45,0 \\
São Paulo & 94.223 & 614.279 & & 124.551 & 982.087 & & 32,0 & 60,0 \\
\hline
\end{tabular}

Fonte: Ministério do Trabalho e Emprego. Dados da Rais.

O Gráfico 4 exemplifica, do total de empregos nas centralidades, quantos conformam novas centralidades. Belo Horizonte, Belém, Rio de Janeiro e São Paulo são as cidades onde as novas centralidades se mostram menos importantes, em termos proporcionais ao total de empregos nas centralidades. Talvez a estrutura de centros e subcentros já esteja mais consolidada nesses espaços urbanos.

Já em cidades como Manaus e Salvador encontramos uma proporção maior de novos empregos nas centralidades do que nas áreas centrais de referência. Nesses municípios a dinâmica de formação de novas áreas concentradoras de empregos parece ser mais forte. 
GRÁFICO 4

Total de empregos nas centralidades e novas centralidades - 2002-2013

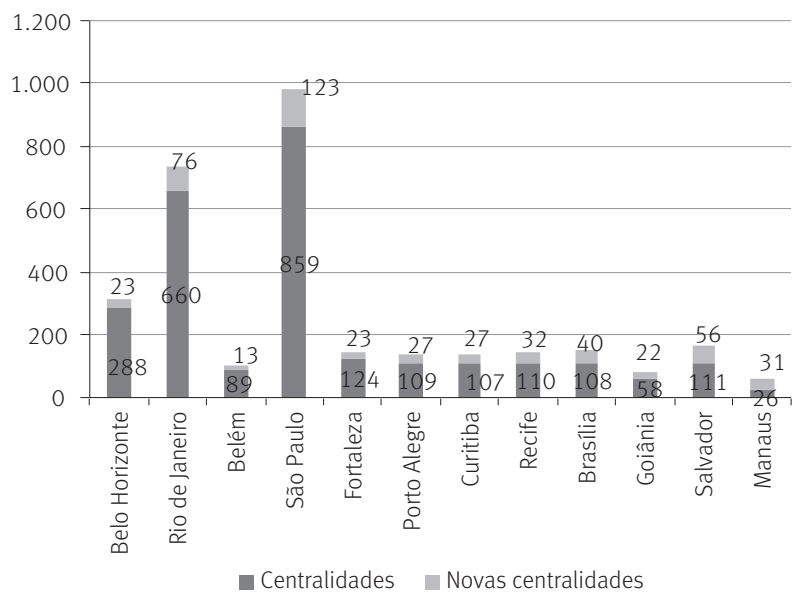

Fonte: Ministério do Trabalho e Emprego. Dados da Rais.

Nota: São consideradas novas centralidades as áreas em centralidades em 2013, que não pertenciam a centralidades em 2002.

Em Belém, conforme mostra a Figura 3, não houve nenhuma sobreposição entre 0 perímetro da área central de referência e as centralidades. Isso pode indicar certo abandono do centro tradicional, a ser verificado in loco. Já para Curitiba, Porto Alegre, Recife e Rio de Janeiro, há grande sobreposição das áreas centrais de referência e das centralidades. Os centros não deixaram de ser importantes. Nos casos de Belo Horizonte e São Paulo, os centros mantêm sua relevância, mas cresceram bastante com relação ao perímetro delimitado.

FIGURA 3

Área central de referência e centralidades Belém - 2002-2013

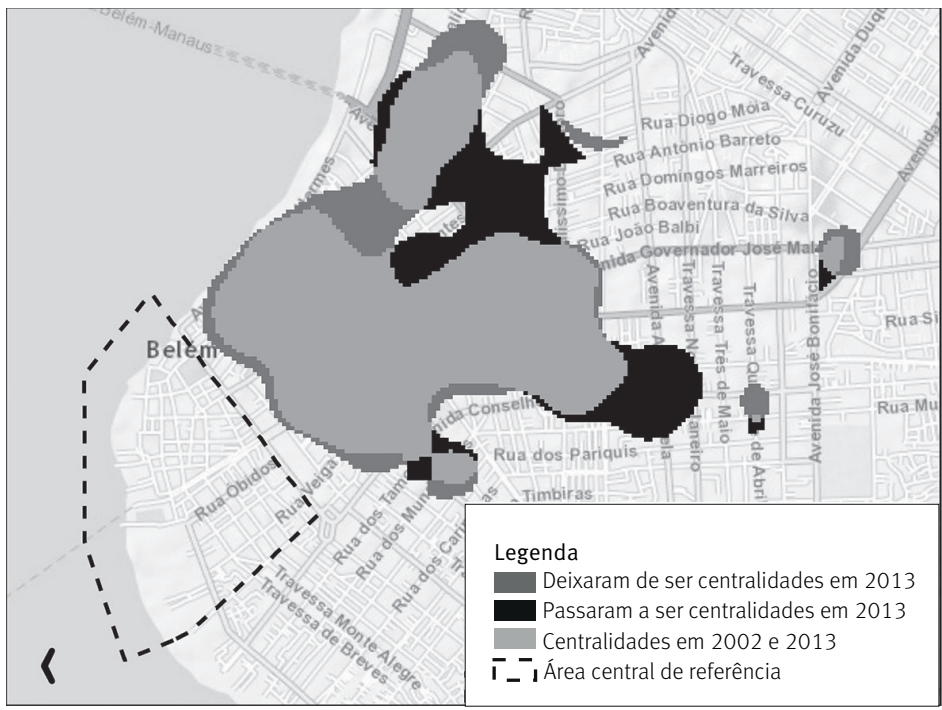

Fonte: Ministério do Trabalho e Emprego. Dados da Rais. 
Com relação às novas centralidades - aquelas que não existiam em 2002 e passaram a existir em 2013 -, nota-se sua pequena dimensão em termos de empregos e área. Em geral, constituem a extensão da borda de alguma centralidade já consolidada, ou, quando indicam o aparecimento de um subcentro distante, são de pequeno porte. Nesse espaço de tempo, Curitiba pareceu ter a estrutura espacial mais dinâmica, onde de fato se visualiza o surgimento de novas centralidades apontando o aparecimento de novos subcentros dispersos no território.

FIGURA 4

Área central de referência e centralidades

Curitiba - 2002-2013

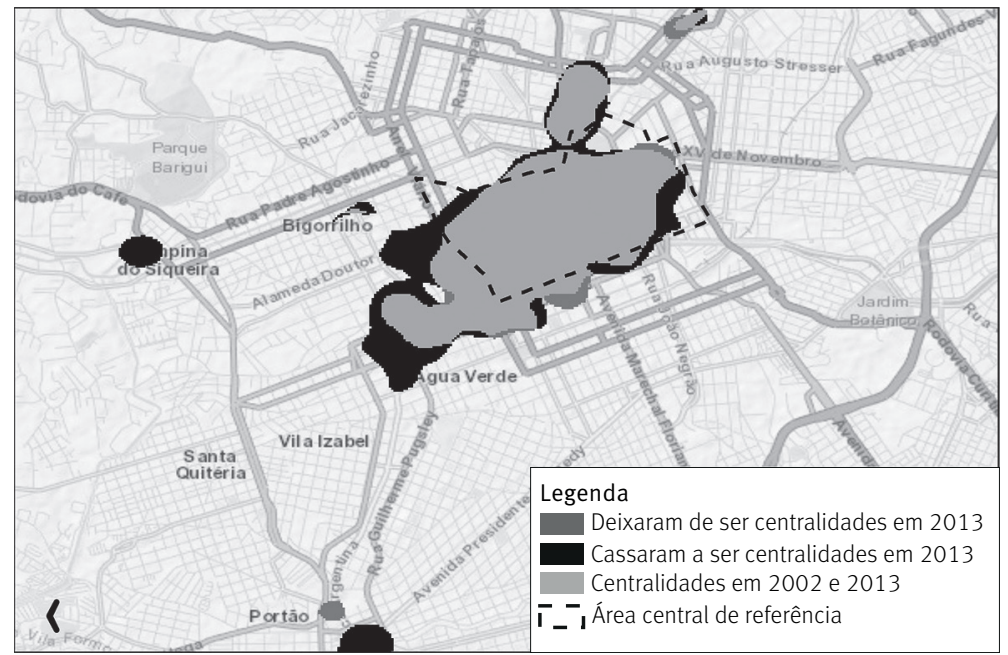

Fonte: Ministério do Trabalho e Emprego. Dados da Rais.

Os mapas das centralidades mostram como a estrutura urbana e o arranjo espacial das zonas de concentração de empregos podem ser muito diferenciados, variando em graus de monocentralidade e policentralidade. Há situações em que o núcleo original cresceu bastante, sem gerar muitos subcentros expressivos (Curitiba e Belo Horizonte), outras em que o núcleo original cresceu, mas outro núcleo expressivo surgiu e rivaliza em porte com o original (Fortaleza e Recife) e ainda estruturas de concentração de empregos com núcleos de tamanho semelhante, porém bastante dispersos (Goiânia, Salvador e Brasília). 0 caso de São Paulo parece o mais policêntrico, pois o núcleo original gerou fragmentos próximos e se alastrou seguindo o caminho sudoeste, além de existirem subcentros consolidados tanto dentro do município quanto na região metropolitana.

Os casos de São Paulo e Rio de Janeiro se destacam dos demais, devido tanto ao porte, são cidades onde o total de empregos nas centralidades é muito maior, quanto à complexidade da estrutura urbana. Os dois casos parecem ser mais policêntricos, com outros municípios da região metropolitana também abrigando importantes polos de concentração de empregos. 
FIGURA 5

Área central de referência e centralidades

São Paulo - 2002-2013

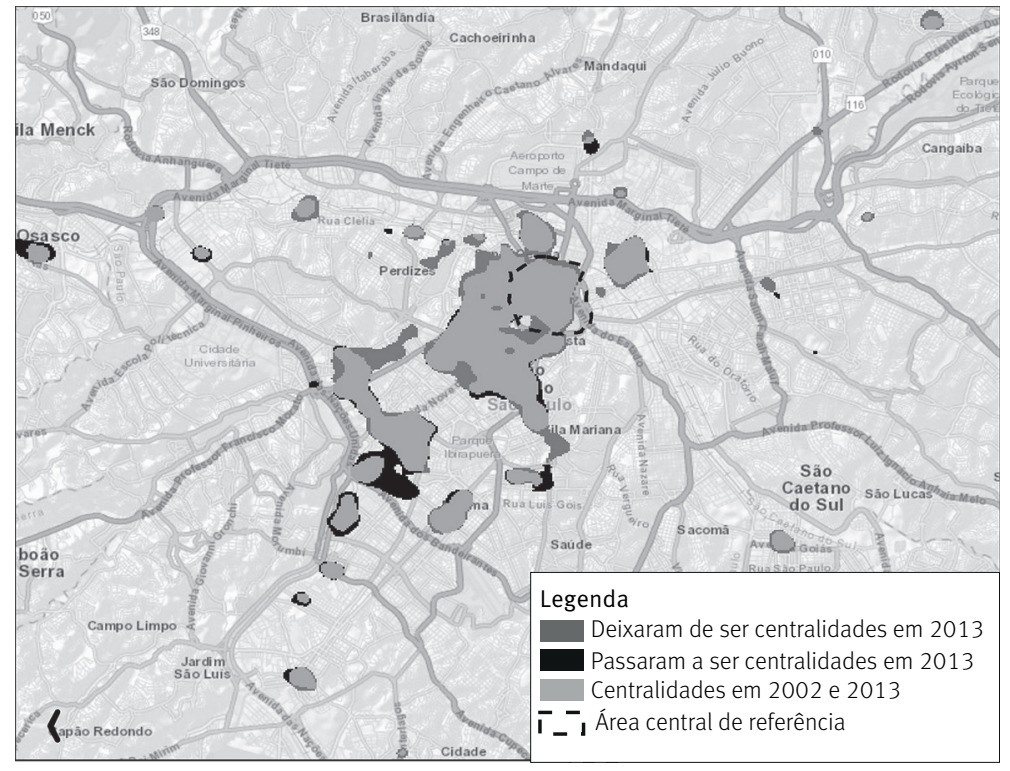

Fonte: Ministério do Trabalho e Emprego. Dados da Rais.

Em São Paulo, o núcleo histórico original gerou fragmentos próximos e se alastrou seguindo o caminho sudoeste. Esse caminho aparece na Figura 5, que apresenta as áreas de centralidades em São Paulo. A análise de Villaça (1998) já apontava esse caminho como o vetor de ocupação das classes mais abastadas, as quais os empregos seguem. Posteriormente, Fix (2007) identifica a continuação do deslocamento das centralidades paulistanas em direção à Marginal Pinheiros.

Já no caso do Rio de Janeiro, o caminho de extravasamento do centro antigo não possui um único vetor. Notam-se outras áreas de aglomeração de empregos já bastante consolidadas, como Niterói, Flamengo, Copacabana, Ipanema e Leblon e a aglomeração mais distante da Barra da Tijuca, que mostrou crescimento no período estudado.

Uma possibilidade de análise desses resultados se abre a partir do campo da sociologia urbana. Tal abordagem teórica tem como um de seus precursores Manuel Castells, que inova ao estudar o fenômeno urbano a partir das grandes transformações das forças produtivas em curso. Por exemplo, o novo "capitalismo informacional global” propiciaria o surgimento de megacidades, grandes aglomerados populacionais com grande dinamismo econômico, inovação e conexão a redes globais (CASTELLS, 1999). Ou seja, grandes empresas transnacionais determinam transformações importantes no território urbano. Já Sassen (1998) ressalta a necessidade de estudar o fenômeno urbano levando em consideração a rede internacional de cidades em que alguns nós são estratégicos, são as cidades globais. Ambos autores enfatizam o papel das empresas dos setores de finanças e serviços 
especializados. Especificamente no estudo de Sassen é relevante, para a análise dos fatos apresentados neste trabalho, a sua visão das causas da localização dos empregos desses setores. 0 foco do trabalho da autora é a hierarquia mundial de cidades, e porque as empresas transnacionais dos setores citados resolvem se concentrar em uma cidade específica.

São Paulo é citada como uma cidade global e está nessa posição hierárquica, apesar de fazer parte de uma economia em desenvolvimento. Ela tem uma posição de primazia no sistema urbano local. Seu tamanho exacerbado justifica-se em face da atração de migrantes rurais, visto ter sido o grande polo industrial do país. Mas seu caráter global não se deveu somente a essa primazia, mas muito mais à chegada das empresas transnacionais que se seguiram à abertura da economia local, com privatizações e atração de investimentos diretos estrangeiros, no final da década de 1990 (SASSEN,1998).

Sassen também menciona a forma urbana que acomoda essa nova cidade global, assim como os espaços que vão aglomerar os empregos dos setores "globalizados". Na Europa, os centros históricos ainda têm vitalidade e são bem cuidados. Então criam-se torres de escritórios inteligentes em bairros distantes, como "la Défense" em Paris. Os norte-americanos, por sua vez, aproveitam grandes vazios urbanos nos centros históricos decadentes para realizar megaprojetos, conglomerados de edifícios urbanos que são minicidades dentro de si. Pouco dialogam com o tecido urbano em volta.

Nesse contexto, o trabalho de Mariana Fix (2007) é detalhista ao historiar o caso de São Paulo. A autora esmiúça os mecanismos que explicam o deslocamento do centro de negócios de São Paulo para a região da Marginal Pinheiros, a partir dos anos 1980 . 0 centro já havia se deslocado para a Avenida Paulista e começado a ocupar a Avenida Faria Lima.

Essencialmente, os novos setores globais demandam um tipo de escritório "inteligente" e uma localização que ressalte esse "status" moderno e global das atividades. Há a mesma lógica de megaprojetos dos Estados Unidos, além de existir alguma integração no circuito global de promoção imobiliária.

Mesmo assim, a autora deixa claras as especificidades de um país em desenvolvimento, no qual a integração global não é completa. Os mecanismos de produção imobiliária do mundo desenvolvido não conseguem se reproduzir totalmente aqui. Não há sistema de crédito semelhante, as taxas de juros são muito altas, não há uma modernização do sistema de crédito imobiliário com securitização das dívidas, por exemplo. Ao mesmo tempo, a integração ao capitalismo global se dá com aumento da polarização de classes sociais dentro da cidade, devido tanto a remoções de favelas que estivessem no caminho da valorização fundiária, quanto à canalização de dinheiro público para confecção de infraestrutura urbana nas áreas dos escritórios, aumentando a desigualdade espacial dentro da cidade.

Para Fix é importante a construção da imagem de cidade global e porque em algumas décadas surgiu um novo skyline em São Paulo, que é o da Marginal Pinheiros. Ao mesmo tempo, alinhada com David Harvey (2008), a autora menciona como o processo de acumulação do capital, que precisa se reinvestir e ter retornos cada vez maiores, influencia 
uma busca constante por encontrar novas áreas, com novos lançamentos de prédios "inteligentes" para continuar abrigando os empregos da cidade global.

Em termos concretos, observamos na Figura 5 a delimitação no espaço de todos esses processos que acabamos de descrever. 0 Centro antigo continua concentrador de empregos, mas, em São Paulo, ele responde por apenas 13\% de todos os empregos em centralidades em 2013, não sendo nem de longe preponderante. Esse percentual é de 34\% para o mesmo ano no Rio de Janeiro. Segundo Sassen (1998), a reconstrução do centro a partir dos padrões de cidade global é diferente dos padrões de aglomeração que vinham acontecendo desde então. A Figura 5 mostra como ainda há concentração nas Avenidas Faria Lima e Berrini. A área mais nova de concentração de empregos, em preto na figura, corresponde ao bairro da Vila Olímpia. Segundo Fix (2007), essa teria sido a última fronteira criada como fachada da cidade global pelo setor imobiliário.

Interessante notar que no Rio de Janeiro não há um vetor tão claro de deslocamento das centralidades. A geografia da cidade é muito peculiar, contribuindo para uma maior fragmentação dos espaços. Mas o Rio não é uma cidade global. A centralidade mais recente, a Barra da Tijuca, ganhou essa condição por causa de seus shoppings centers. Não é centro de comando e poder do sistema global de cidades.

Esse padrão de aglomeração, que não é o da cidade global, mas que responde às necessidades urbanas de concentrar atividades em um local, também se verifica nas outras cidades de centros "fortes", como Belo Horizonte, Curitiba, Manaus e Porto Alegre. Já nos casos de Salvador e Belém, verificamos como os seus centros históricos desvitalizados não perdem primazia por uma necessidade de criar novos espaços de comando e poder, vinculados à economia global, mas sim devido à dificuldade de manter os centros históricos como espaços de aglomeração atraentes.

\section{Considerações finais}

Este trabalho analisa a perda de primazia dos centros históricos, utilizando conceituação de áreas centrais, centralidades e novas centralidades para descrever a dinâmica populacional e de empregos nas 12 maiores RMs brasileiras nos períodos 1991-2000-2010 e 2002-2013.

As áreas centrais de referência foram definidas de acordo com a divisão administrativa do município e utilizadas para resgatar o que cada cidade identifica como seu centro, com forte sentido simbólico. A definição das centralidades é feita a partir dos resultados da aplicação da metodologia aos dados de cada cidade. Nesse sentido, é uma conceituação técnica e idêntica, pois segue a mesma metodologia para todas as cidades.

Dessa primeira abordagem, verificou-se razoável variabilidade entre as capitais em relação a semelhanças ou diferenças entre suas áreas centrais e centralidades, a localização do poder simbólico e atrator. Já no que se refere à dinâmica populacional, entre 1991 e 2000 , verificou-se perda de população. Por outro lado, ocorreu recuperação no período 
seguinte (2000-2010). Por sua vez, a comprovação do ganho de empregos entre 2002 e 2013, nas áreas centrais de referência, pode indicar possível explicação no tocante à volta da população para essas áreas, que pode ter se estabelecido próximo ao local de trabalho. Mesmo assim, há perda proporcional de empregos em relação ao restante do município central e da RM como um todo, uma vez que o crescimento destes no centro ocorreu a taxas menores do que nos municípios e RMs, verificando-se desconcentração de empregos nas áreas centrais de referência. Esse fenômeno foi observado a partir da consolidação das centralidades já presentes em 2002 e do surgimento de novas centralidades entre 2002 e 2013, contínuas ou não às áreas de concentração de empregos.

As centralidades e as novas centralidades indicaram como, em algumas cidades, houve extravasamento dos empregos da área central de referência e, em outras, existem polos diferenciados e espacialmente distintos, indicando estruturas urbanas diferentes entre as metrópoles estudadas. Sob esse aspecto, o cenário é bastante diverso entre as metrópoles estudadas e varia em graus de monocentralidade e policentralidade. Com isso, confirma-se a complexificação da dinâmica de concentração de pessoas e empregos na escala intraurbana para as regiões metropolitanas analisadas, observando-se manutenção da primazia de alguns centros antigos tradicionais e, ao mesmo tempo, criação de novas centralidades, conforme conceituado no texto.

A análise dos empregos ficou restrita à disponibilidade das informações de endereçamento correto e formalidade do trabalho disponível na base de dados. Assim, os resultados desta pesquisa são restritos aos setores analisados, e poderiam ser diferentes caso a completude dos dados estivesse disponível.

A identificação desses movimentos populacionais e de empregos, bastante abrangentes entre as 12 metrópoles estudadas, abre espaço para diversos questionamentos e possíveis direcionamentos da ação do poder público sobre essas realidades urbanas. Estudos mais aprofundados em cada realidade local podem indicar como reforçar a vocação das áreas identificadas e estimular os efeitos positivos dessas aglomerações, para que haja maior crescimento econômico e incentivo ao desenvolvimento de subcentralidades.

\section{Referências}

ALVES, H. P. da F.; ALVES, C. D.; PEREIRA, M. N.; MONTEIRO, A. M. V. Dinâmicas de urbanização na hiperperiferia da metrópole de São Paulo: análise dos processos de expansão urbana e das situações de vulnerabilidade socioambiental em escala intraurbana. Revista Brasileira de Estudos de População, v. 27, n. 1, p. 141-159, jan./jun. 2010.

BENEVOLO, L. The history of the city. London: Scholar Press, 1980.

BERNARDINO, I. L.; LACERDA, N. Centros históricos brasileiros: tensões entre a obsolescência imobiliária e a construção de novas espacialidades. Revista Brasileira de Estudos Urbanos e Regionais, v. 17, n. 1, p. 61-74, 2015.

BETTENCOURT, L. M. A. Cities as complex systems. In: FURTADO, B. A.; SAKOWSKI, P. A. M.; TÓVOLLI, M. H. (Ed.). Modeling complex systems for public policies. Brasília: Ipea, 2015. p. 217-238. 
BÓGUS, L. M. M.; SOUSA, A. M. L. de. Habitação em centros históricos: um desafio à integração das políticas públicas. Cadernos Metrópole, v. 18, n. 37, p. 845-861, 2016.

BRASIL. Ministério das Cidades. Reabilitação de centros urbanos. Brasília: Ministério das Cidades, 2005.

BRASIL. Ministério do Trabalho e Emprego. Relação Anual de Informações Sociais: 2003-2012. Brasília: MTE, 2013.

CASTELLS. M. A sociedade em rede. São Paulo: Paz e Terra, 1999.

CULLEN, G. Townscape. London, 1961.

CUNHA, J. M. P. da. Aglomerações urbanas e mobilidade populacional: o caso da Região Metropolitana de Campinas. Revista Brasileira de Estudos de População, v. 33, n. 1, p. 99-128, jan./jun. 2016.

CUNHA, T. A. da; CUNHA, J. M. P. da; JAKOB, A. A. E. Dinâmica intraurbana e redes sociais na Baixada Santista. Revista Brasileira de Estudos de População, v. 30, n. 1, p. 7-33, jan./jun. 2013.

EHRENHALT, A. The great inversion and the future of the American city. New York: Vitage Books, 2012.

EHRL, P. Minimum comparable areas for the period 1872-2010: an aggregation of Brazilian municipalities. Estudos Econômicos (São Paulo), v. 47, n. 1, p. 215-229, 2017.

FIX, M. São Paulo, cidade global: fundamentos financeiros de uma miragem. São Paulo: Boitempo, 2007.

FRÚGOLI JR., H. Centralidade em São Paulo: trajetórias, conflitos e negociações na metrópole. 2. ed. São Paulo: Edusp, 2000.

FURTADO, B. A. Neighbourhoods in urban economics incorporating cognitively perceived urban space in economic models. Urban Studies, v. 48, n. 13, p. 2827-2847, 2011.

GALSTER, G. On the nature of neighbourhood. Urban Studies, v. 38, n. 12, p. 2111-2124, 2001.

GAY, A. L.; VALVERDE, J. R. La renovación sociodemográfica de un centro urbano maduro: perfiles migratorios y filtros residenciales en la ciudad de Barcelona. Scripta Nova, v. 12, n. 270, p. 741798, 2008.

GLAESER, E. L. Triumph of the city: how our greatest invention makes us richer, smarter, greener, healthier, and happier. New York, NY: Penguin Books, 2012.

GOTTDIENER, M. A produção social do espaço urbano. São Paulo: Edusp, 1997.

GRIGSBY, W.; BARATZ, G.; GALSTER, G.; MACLENNAN, D.; HALLMAN, H. The dynamics of neighbourhood change and decline. London: Pergamon, 1987.

HARVEY, D. The right to the city. New Left Review, v. 53, p. 23-40, 2008.

IBGE - Instituo Brasileiro de Geografia e Estatística. Censo Demográfico 1991: agregado por setores censitários dos resultados do universo. Rio de Janeiro: IBGE, 1991.

Censo Demográfico 2000: agregado por setores censitários dos resultados do universo. Rio de Janeiro: IBGE, v. 2a, 2003.

. Censo Demográfico 2010. Rio de Janeiro: IBGE, 2013. Disponivel em: 〈http://www. censo2010.ibge.gov.br/sinopse/index.php?dados=8>. Acesso em: 19 fev. 2016.

Regiões de influência das cidades. Rio de Janeiro: IBGE, 2008.

JACOBS, J. Morte e vida de grandes cidades. São Paulo: Martins Fontes, 2000. 
. The economy of cities. New York: Vintage Books, 1970.

JANNUZZI, P. de M.; JANNUZZI, N. Crescimento urbano, saldos migratórios e atratividade residencial dos distritos da cidade de São Paulo: 1980-2000. Revista Brasileira de Estudos Urbanos e Regionais, v. 4, n. 1/2, p. 107-127, 2002.

LESLIE, T. Identification and differentiation of urban centers in Phoenix through a multi-criteria Kernel-density approach. International Regional Science Review, v. 32, n. 2, p. 205-235, 2010.

LYNCH, K.; CAMARGO, J. L. The image of the city. São Paulo: Martins Fontes, 1960.

MARQUES, E. Estrutura social e segregação em São Paulo: transformações na década de 2000. Dados - Revista de Ciências Sociais, v. 57, n. 3, p. 675-710, 2014.

MARQUES, E.; REQUENA, C. O centro voltou a crescer? Trajetórias demográficas diversas e heterogeneidade na São Paulo dos anos 2000. Novos Estudos CEBRAP, n. 95, p. 17-37, 2013.

MATION, L. Criação de áreas mínimas comparáveis (AMCs) para setores censitários de 1980 a 2010. Brasília: Ipea, no prelo (Textos para Discussão).

NADALIN, V.; IGLIORI, D. Espraiamento urbano e periferização da pobreza na região metropolitana de São Paulo: evidências empíricas. EURE, v. 41, n. 124, p. 91-111, 2015.

O’SULLIVAN, D.; UNWIN, D. Geographic information analysis. John Wiley \& Sons, 2014.

PEREIRA, R. H.; NADALIN, V., MONASTERIO, L.; ALBUQUERQUE, P. H. Urban centrality: a simple index. Geographical Analysis, v. 45, n. 1, p. 77-89, 2013.

RODRIGUES, A. L. Ingovernabilidade metropolitana e segregação espacial: receita para a explosão da violência. In: FURTADO, B. A.; KRAUSE, C.; FRANÇA, K. Território metropolitano, políticas municipais. Brasília: Ipea, 2013. p. 53-82.

SASSEN, S. As cidades na economia mundial. São Paulo: Studio Nobel, 1998.

SITTE, C. City planning according to artistic principles. London: Columbia University Studies in Art History and Archaeology, 1889.

STORPER, M.; VENABLES, A. J. O burburinho: a força econômica da cidade. In: DINIZ, C. C.; LEMOS, M. B. (Org.). Economia e território. Belo Horizonte: Editora da UFMG, 2005. p. 21-56.

THURSTAIN-GOODWIN, M.; UNWIN, D. Defining and delineating the central areas of towns for statistical monitoring using continuous surface representations. Transactions in GIS, v. 4, n. 4, p. 305-317, 2000.

VILLAÇA, F. Espaço intra-urbano no Brasil. São Paulo: Studio Nobel, 1998.

\section{Sobre os autores}

Vanessa Gapriotti Nadalin é doutora em Teoria Econômica pela Faculdade de Economia e Administração da Universidade de São Paulo (FEA/USP). Técnica de Planejamento e Pesquisa, no Instituto de Pesquisas Econômicas Aplicadas (Ipea).

Bernardo Alves Furtado é doutor em Economia pelo Centro de Desenvolvimento e Planejamento Regional da Universidade Federal de Minas Gerais (Cedeplar/UFMG). Técnico de Planejamento e Pesquisa no Instituto de Pesquisas Econômicas Aplicadas (Ipea).

Matheus Rabetti é bacharel em Estatística na Universidade de Brasília (UnB). Cientista de dados na Globo.com. 


\title{
Endereço para correspondência
}

\author{
Vanessa Gapriotti Nadalin \\ Setor Bancário Sul Q. 1 Ed. BNDES \\ 70076-900 - Brasília-DF, Brasil \\ Bernardo Alves Furtado \\ Setor Bancário Sul Q. 1 Ed. BNDES, sala 1110 \\ 70076-900 - Brasília-DF, Brasil \\ Matheus Rabetti \\ Avenida Marechal Henrique Lott, 70, apto. 714, Barra da Tijuca \\ 22631-907 - Rio de Janeiro-RJ, Brasil
}

\begin{abstract}
Intraurban concentration of people and jobs: have Brazilian inner cities lost their primacy?

Historical city centers are those regions internal to a metropolis that deserve special attention since, despite their symbolic value, they are prone to fall into decadence and become abandoned. The spatial pattern of metropolitan population and employment determines the locational importance of urban sites, displacement flows and even the vitality of each urban portion of the territory, including the city center. In spite of that, intraurban population location data are available only every ten years. Data on job location, when available, are aggregated and not geocoded. In that context, this article analyses and identifies intraurban population (1991, 2000 and 2010) and employment (2002 and 2013) structures, for 12 Brazilian metropolitan areas, using (a) Minimum comparable Areas to aggregate population Census data and (b) jobs location with identification. Results indicate that there is population loss in metropolitan centers for the 19912000 period, partly recovered in the following decade. It is also verified that jobs have spread from traditional city centers, with migration to new central areas. Moreover, the behavior is not linear for each of the 12 areas analyzed and the final spatial result is specific to each of them. This article contributes with the original finding of the spatial location of jobs for the 12 metro areas. Finally, the methodology developed enables a standardized quantitative urban analysis which may support researchers with local knowledge.
\end{abstract}

Keywords: Intraurban jobs. Central urban areas. Population displacement. Kernel density. Metropolitan regions.

\section{Resumen}

¿Concentración intraurbana de población y puestos de trabajo: los centros antiguos de las ciudades brasileñas perdieron primacía?

Los centros antiguos de las ciudades son regiones internas de las metrópolis que se destacan por su valor simbólico y por estar sometidas a procesos de deterioro y abandono. En general, la configuración espacial de la población y de los empleos determina la relevancia de la ubicación de los sitios urbanos, los flujos de movilidad y la vitalidad propia de cada porción urbana, incluso para el análisis del centro. Asimismo, datos de ubicación poblacional intraurbana 
solamente están disponibles a cada diez años. Datos de ubicación de puestos de trabajo, de estar disponibles, se encuentran agregados y no están georreferenciados. En este contexto, este trabajo analiza e identifica estructuras intraurbanas de población (1991, 2000 y 2010) y empleo (2002 y 2013) en 12 regiones metropolitanas brasileñas, utilizando a) áreas mínimas comparables para agregar datos poblacionales censitarios y b) georreferenciación identificada de empleos. Los resultados indican que hay pérdida poblacional en los centros metropolitanos en el período 1991-2000, que se recupera parcialmente en el decenio siguiente. Además se constata la desconcentración de empleos con migración hacia nuevas áreas centrales en relación con los centros urbanos tradicionales. A su vez, el comportamiento de cada una de las 12 metrópolis analizadas no es lineal y el resultado espacial final es específico para cada una de ellas. El artículo contribuye con una construcción inédita de la espacialización de los puestos de trabajo para las 12 regiones metropolitanas. Por último, la metodología desarrollada permite el análisis urbano cuantitativo homogeneizado como apoyo a investigadores con conocimiento local.

Palabras clave: Empleo intraurbano. Áreas centrales urbanas. Desplazamiento poblacional. Densidad de Kernel. Regiones metropolitanas.

Recebido para publicação em 14/08/2017

Aceito para publicação em 16/04/2018 